\title{
ORIGINAL ARTICLE Retargeted adenoviruses for radiation-guided gene delivery
}

\author{
SA Kaliberov ${ }^{1,2}$, LN Kaliberova ${ }^{1,2}$, H Yan $^{1,2}$, V Kapoor ${ }^{1}$ and DE Hallahan ${ }^{1,2,3}$
}

The combination of radiation with radiosensitizing gene delivery or oncolytic viruses promises to provide an advantage that could improve the therapeutic results for glioblastoma. X-rays can induce significant molecular changes in cancer cells. We isolated the GIRLRG peptide that binds to radiation-inducible $78 \mathrm{kDa}$ glucose-regulated protein (GRP78), which is overexpressed on the plasma membranes of irradiated cancer cells and tumor-associated microvascular endothelial cells. The goal of our study was to improve tumor-specific adenovirus-mediated gene delivery by selectively targeting the adenovirus binding to this radiation-inducible protein. We employed an adenoviral fiber replacement approach to conduct a study of the targeting utility of GRP78-binding peptide. We have developed fiber-modified adenoviruses encoding the GRP78-binding peptide inserted into the fiber-fibritin. We have evaluated the reporter gene expression of fiber-modified adenoviruses in vitro using a panel of glioma cells and a human D54MG tumor xenograft model. The obtained results demonstrated that employment of the GRP78-binding peptide resulted in increased gene expression in irradiated tumors following infection with fiber-modified adenoviruses, compared with untreated tumor cells. These studies demonstrate the feasibility of adenoviral retargeting using the GRP78-binding peptide that selectively recognizes tumor cells responding to radiation treatment.

Cancer Gene Therapy (2016) 23, 303-314; doi:10.1038/cgt.2016.32; published online 5 August 2016

\section{INTRODUCTION}

Malignant brain tumors pose an unprecedented challenge to developing novel, safe and effective therapies that can be integrated into the traditional therapeutic tripod of surgery, chemotherapy and radiotherapy (XRT). ${ }^{1}$ Glioblastoma multiforme is the most common and highly lethal primary neoplasm of the central nervous system. Unusual resistance of glioblastoma multiforme to radiation and chemotherapy, their highly invasive nature and their remarkable heterogeneity that reflects the genomic instability of these tumor cells contribute substantially to the sad fact that patient median survival has not changed appreciably in the last few decades despite highly aggressive therapeutic approaches. ${ }^{2,3}$

Radiation treatment is a well-established modality for cancer therapy. Approximately half of the patients with central nervous system cancer worldwide are treated with XRT in combination with chemotherapy or surgery. Radiation therapy is, in general, localized and noninvasive and does not produce systemic toxicity after treatment in comparison with chemotherapy. Although in recent years significant progress in XRT methods has been achieved, development of resistance to irradiation remains a major problem for successful disease control. Intratumoral delivery of therapeutic genes has the potential to become a powerful alternative method of drug delivery. Over the last decade, extensive progress in XRT and gene therapy combinatorial approaches has been achieved to overcome the resistance of tumor cells to irradiation. These efforts for development of cancer gene therapy agents in combination with radiation include the use of transductional and transcriptional approaches for targeting of adenovirus (Ad) vectors. Transcriptional control of therapeutic gene expression using promoters that are responsive to ionizing radiation provides an attractive approach for a combination of gene therapy and XRT. It has been shown that XRT can modulate the expression of a large number of cellular genes involved in the early response of tumor cells to ionizing radiation-mediated damage. This includes genes involved in cell cycle checkpoints, cellular stress, DNA repair and apoptosis. ${ }^{4}$

The main factor currently limiting the clinical potential of gene therapy is the poor level of in situ tumor cell transduction achievable by existing gene transfer approaches. ${ }^{5}$ Nevertheless, Ad-based vectors are particularly attractive because of a wellcharacterized mechanism of cellular entry and a propensity to infect a wide variety of cell types efficiently within the central nervous system. ${ }^{6-8}$ Ad vectors have shown utility in a number of animal models of glioma and have been investigated in several clinical trials in adult patients with malignant glioblastomas., ${ }^{9,10}$ As all these studies employ direct intratumoral or intracavitary injection, expression of receptors for Ad binding on these tumors will likely determine the overall success of these and future Ad cancer gene therapy trials. Important advances in the combination of irradiation and gene therapy over the last decade are a result of improved understanding of the molecular mechanisms that mediate cancer progression and resistance to XRT.

Data from experimental and clinical studies indicate that ionizing radiation produces DNA damage and activates multiple intracellular signaling pathways. New antigens are thereby overexpressed and exposed on the cell membrane following XRT. Phage display technology was exploited to identify peptides that bind selectively to these XRT-induced neoantigens. Phage biopanning identified peptides targeting the glucose-regulated protein 78 (GRP78). ${ }^{11}$ Several studies have revealed the upregulation of the GRP78 expression associated with therapy resistance of

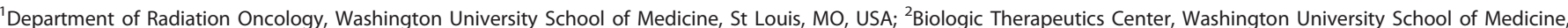
St Louis, MO, USA and ${ }^{3}$ Siteman Cancer Center, St Louis, MO, USA. Correspondence: Dr SA Kaliberov, Department of Radiation Oncology, Washington University School of Medicine, 660 South Euclid Avenue, Campus Box 8224, St Louis, MO 63108, USA.
} 
tumor cells. ${ }^{12}$ Moreover, GRP78/BiP relocates to the cell membrane in malignant but not in benign cells. ${ }^{13}$

In this study, we have explored the utility of novel peptides that specifically bind to XRT-induced neoantigens to achieve targeted Ad-mediated gene transfer. Incorporation of the GRP78-binding peptides into the fiber protein of the viral capsid was used to modify tropism for Ad targeting. The results demonstrated that employment of this modified fiber increased Ad-mediated gene transfer in irradiated glioma cells. This finding provides a novel approach for Ad gene delivery targeting to sites treated with XRT.

\section{MATERIALS AND METHODS}

\section{Cells and reagents}

293F28 cells expressing wild-type Ad5 fiber protein have been described previously. ${ }^{14}$ Human glioma cell lines D54MG and U251MG (originally obtained from $\operatorname{Dr} D$ Bigner, Duke University, Durham, NC), human glioblastoma U87MG cells (HTB-14, American Type Culture Collection, Manassas, VA, USA) and human embryonic kidney HEK293 (Microbix Biosystems, Toronto, ON, Canada) cells were cultured in DMEM/F12 (Mediatech, Herndon, VA, USA) containing $10 \%$ fetal bovine serum (Summit Biotechnology, Fort Collins, CO, USA). All cells were tested for mycoplasma (MycoAlert Mycoplasma Detection Kit, Lonza, Rockland, ME, USA) and cultured in a humidified atmosphere with $5 \% \mathrm{CO}_{2}$ at $37^{\circ} \mathrm{C}$. The recombinant enzymes were purchased from New England Biolabs (Ipswich, MA, USA).

\section{RNA preparation and RT-PCR}

The levels of GRP78 messenger RNA were determined by reverse transcriptase (RT-PCR). Total RNA was extracted using the RNeasy Mini Kit (Qiagen, Valencia, CA, USA) and quantified spectrophotometrically using an MBA2000 spectrophotometer (Perkin Elmer, Wellesley, MA, USA). complimentary DNA (CDNA) was synthesized using random hexamer primers and an Omniscript RT kit (Qiagen). The first-strand CDNA was used as the template for PCR. For amplification of CDNA encoding GRP78, GRP78f sense and GRP78r antisense primers were used (Table 1). Human glyceraldehyde 3-phosphate dehydrogenase (GAPDH) CDNA was used as an internal standard for template loading of PCR by using the GAPDH forward and GAPDH reverse primers (Table 1). PCR was performed under the following conditions: 30 cycles at $95^{\circ} \mathrm{C}$ for $45 \mathrm{~s}$, at $55^{\circ} \mathrm{C}$ for $45 \mathrm{~s}$ and at $72{ }^{\circ} \mathrm{C}$ for $1 \mathrm{~min}$. PCR products were analyzed by $0.6 \%$ agarose electrophoresis followed by ethidium bromide staining. The relative abundance of each PCR product was determined by semiquantitative analysis of digital photographs of gels using Labworks 4.6 software (UVP Products, Upland, CA, USA). The integral optical density values of GRP78 and GAPDH were measured. The ratio of the integral optical density of GRP78 to GAPDH was used to express the relative level of GRP78 mRNA.

\section{FACS analysis}

To determine the levels of hCAR and aV $33 / a V B 5$ integrin expression, cells were seeded at $5 \times 10^{5}$ cells per well in 6 -well tissue culture plates and allowed to grow overnight. The next day, the wells were washed with phosphate-buffered saline (PBS), and cells were collected and subjected to fluorescence-activated cell sorter (FACS) analysis. For evaluation of $a V \beta 3 / a V \beta 5$ integrin expression, cells were stained with anti-integrin aV $\beta 3$ antibody, clone LM609, and anti-integrin aV 35 antibody, clone P1F6 (MAB1976 and MAB1961, respectively, Millipore, Billerica, MA, USA), and an anti-mouse AlexaFluor 488-labeled goat lgG (R37120, Molecular Probes, Eugene, OR, USA). In addition, cells were evaluated for hCAR expression using anti-CAR antibody (RmCB, 05-644, Millipore) and an antimouse AlexaFluor 488-labeled goat IgG (R37120, Molecular Probes). Mouse IgG1 negative control, clone Ci4 (MABC002, Millipore), was used as isotype control. Cells were incubated with Abs for $1 \mathrm{~h}$ at $4{ }^{\circ} \mathrm{C}$. Following incubation with secondary Abs, the cells were collected, washed three times in FACS buffer, and $\sim 1 \times 10^{4}$ cells were illuminated at $488 \mathrm{~nm}$ and fluorescence was detected in the fluorescein isothiocyanate $(525 / 20 \mathrm{~nm})$ channel using MACSQuant flow cytometer (Miltenyi Biotec, San Diego, CA, USA). Data were analyzed using FlowJo software (Tree Star, Ashland, OR, USA).

D54MG cells were irradiated with either a single dose of $6 \mathrm{~Gy}$ or with three fractions of $3 \mathrm{~Gy}$. Cells were harvested at different time points after irradiation and stained for evaluation of the cell surface expression of GRP78. Briefly, $1 \times 10^{5}$ cells were incubated with anti-GRP78 rabbit monoclonal antibody or isotype control (ab108614 and ab199376, respectively, Abcam, Cambridge, MA, USA) for $1 \mathrm{~h}$ on ice. After washing with PBS, cells were incubated with Alexa Flour 488-conjugated anti-rabbit antibody (ab150077, Abcam) for $1 \mathrm{~h}$ on ice. Cells were washed with PBS and subjected to FACS analysis as described above. Propidium iodide $\left(5 \mathrm{\mu g} \mathrm{ml}^{-1}\right)$ was added for the exclusion of dead cells just before the acquisition. Overlay histograms were prepared using FlowJo software (Tree Star)

\section{Immunocytochemistry}

Human glioma D54MG cells were allowed to grow to reach $75 \%$ confluency and then irradiated three times at 3 Gy over $24 \mathrm{~h}$. The cells were washed one time with warmed PBS and then detached using cold PBS. The cells were counted and mounted on superfrost/plus microscope slides (Fisher Scientific, Waltham, MA, USA). The slides were dried in air and then fixed with $4 \%$ paraformaldehyde for $10 \mathrm{~min}$. For immunocytochemistry assay, air-dried smears were rehydrated in PBS, endogenous horseradish peroxidase (HRP) activity was quenched, blocked with $5 \%$ bovine serum albumin (BSA) plus 5\% normal goat serum, and incubated with anti-GRP78 monoclonal antibody and isotype control (ab108615 and ab172730, respectively, Abcam) for 90 min in a humid chamber. The slides were washed three times with PBS, and smears were incubated for 90 min with a goat anti-mouse IgG Fc-HRP-conjugated secondary antibody (115036-068, Jackson ImmunoResearch, West Grove, PA, USA) diluted in PBS with $0.05 \%$ Tween 20 . The slides were washed with PBS and a 3,3'diaminobenzidine tetrahydrochloride substrate was added on individual smears for immunocytochemistry staining using peroxidase-based detection. The reaction was stopped and hematoxylin counter staining was performed. Finally, the slides were dehydrated by passing gradient ethanol, following by xylene, and then mounted by coverslips with permount gel (Fisher Scientific).

\section{Adenoviral vectors}

Replication-incompetent $E 1$-deleted Ad5 vectors were created using a twoplasmid rescue method. The chimeric fiber-fibritin protein contained the knobless Ad5 fiber tail region fused to the trimerizing foldon domain of the bacteriophage T4 fibritin, followed by peptide linker connecting to the binding peptide open reading frame as described previously. ${ }^{15}$ To

Table 1. $P C R$ primers used for generation and evaluation of fiber-modified Ads

\begin{tabular}{ll}
\hline Name & Sequence $5^{\prime} \rightarrow 3^{\prime}$ \\
\hline BamH1-GRP78-BP & $5^{\prime}$-cataggatccggcggtggcggtaaaaagaaaggtggcggtggcattcgcct-3' \\
GRP78-BP-Swa1 & $5^{\prime}$-tgccatttaaattcagccgcgcaggcgaatgccaccgccacctttct-3' \\
F+100 (32945-32924) & $5^{\prime}$-GAGGTGGCAGGTTGAATACTAG-3' \\
F-100 (30948-30969) & $5^{\prime}$-CCTCCTGGCTGCAAACTTCTC-3' \\
GRP78f & $5^{\prime}$-GATAATCAACCAACTGTTAC-3' \\
GRP78r & $5^{\prime}$-GTATCCTCTTCACCAGTTGG-3' \\
GAPDH forward & $5^{\prime}$-TCCCATCACCATCTTCCA-3' \\
GAPDH reverse & $5^{\prime}$-CATCACGCCACAGTTCC-3' \\
\hline
\end{tabular}

Abbreviations: Ad, adenovirus; GAPDH, glyceraldehyde 3-phosphate dehydrogenase; GRP78, glucose-regulated protein 78. 
generate a PCR product encoding a fragment of the binding peptide open reading frames-specific primers were used (Table 1). The PCR product was cloned into a plasmid pKan566FF using BamHI and Swal sites to generate pKan566FF-GRP78-BP. Insertion sequences were confirmed by using restriction enzyme mapping and partial sequence analysis. The shuttle plasmids were digested using EcoRI and Sall enzymes and integrated into the Ad5 genome by homologous recombination in the Escherichia coli strain BJ5183 with pVK700 or pVK900 plasmid comprising the human cytomegalovirus major immediate-early enhancer/promoter element coupled to the firefly luciferase (Luc) or enhanced green fluorescent protein (eGFP) genes, respectively, followed by the bovine growth hormone polyadenylation signal. The recombinant viral genomes with binding peptide-fiber-fibritin fusions were linearized with PaCl and then transfected into 293 F28 cells stably expressing the native Ad5 fiber ${ }^{14}$ using SuperFect Transfection Reagent (Qiagen, Chatsworth, CA). Following an additional round of amplification on $293 \mathrm{~F} 28$ cells, the viruses were amplified in HEK293 cells and purified twice by $\mathrm{CsCl}$ gradient centrifugation and dialyzed against PBS with $10 \%$ glycerol as previously described. ${ }^{16}$ To verify inserted modifications of the fiber gene all viral genomes were subjected to partial sequencing analysis. The concentration of physical viral particles (vp) was determined by measuring the absorbance of the dissociated virus at $A_{260} \mathrm{~nm}$ using a conversion factor of $1.1 \times 10^{12} \mathrm{vp}$ per absorbance unit. ${ }^{17}$ The multiplicity of infection for subsequent experiments was expressed as vp per cell.

\section{Polymerase chain reaction}

To confirm the presence of chimeric fiber-fibritin genes in the $\mathrm{Ad}$ genomes, viral genomic DNA was extracted from $1 \times 10^{7} \mathrm{vp}$ of purified viral stock by using a QIAamp DNA Mini Kit (Qiagen). For detection of the Ad fiber gene, F-100 sense and $\mathrm{F}+100$ antisense primers were used (Table 1). After the initial denaturation $\left(5 \mathrm{~min}\right.$ at $\left.95^{\circ} \mathrm{C}\right)$, amplification was performed with 30 cycles at $95^{\circ} \mathrm{C}$ for $15 \mathrm{~s}$, at $60^{\circ} \mathrm{C}$ for $1 \mathrm{~min}$, and at $72^{\circ} \mathrm{C}$ for $1 \mathrm{~min}$, and a final extension of $10 \mathrm{~min}$ at $72^{\circ} \mathrm{C}$. PCR products were analyzed by $0.6 \%$ agarose electrophoresis with ethidium bromide staining.

\section{Western blot assay}

For evaluation of fiber-fibritin expression the samples containing $5 \times 10^{9} \mathrm{vp}$ were preincubated in Laemmli sample buffer for 10 min at $99^{\circ} \mathrm{C}$ or at $25^{\circ} \mathrm{C}$ for semi-native conditions. Proteins were separated using a $4-20 \%$ gradient polyacrylamide Precise Protein gel (Thermo Scientific, Wilmington, $D E, U S A)$. The proteins were blotted onto polyvinylidene difluoride membrane membranes and developed with the Sigma FAST 3,3'diaminobenzidine system (Sigma-Aldrich, St Louis, MO, USA) according to the manufacturer's protocol. Anti-adenovirus fiber monoclonal antibody (Ab-4 (clone 4D2); MS-1027, Thermo Scientific) and polyclonal goat antimouse Ig-HRP (P0447, DakoCytomation Denmark A/S, Glostrup, Denmark) were used for Ad fiber protein detection.

The level of GRP78/BiP protein expression was also determined by immunoblotting techniques. Briefly, cells were collected and washed in Tris-buffered saline (TBS, $135 \mathrm{~mm} \mathrm{NaCl}, 2.5 \mathrm{~mm} \mathrm{KCl}, 25 \mathrm{~mm}$ Tris- $\mathrm{HCl}$ and $\mathrm{pH}$ 7.5) and homogenized in ice-cold lysis buffer $(50 \mathrm{~mm}$ Tris- $\mathrm{HCl}, 150 \mathrm{~mm} \mathrm{NaCl}$, 2 mм EDTA and 1\% IGEPAL CA-630 (Sigma-Aldrich). The homogenate was centrifuged at $14000 \times g$ for $5 \mathrm{~min}$ and the protein concentration was determined by the Biuret method using the BCA Protein Assay Kit (Pierce, Rockford, IL, USA). Each sample was denatured for $5 \mathrm{~min}$ at $99^{\circ} \mathrm{C}$ in loading buffer and separated on SDS-PAGE using a $4-20 \%$ gradient polyacrylamide Precise Protein gel (Thermo Scientific) followed by transfer to a polyvinylidene difluoride membrane (Millipore). The membrane was blocked with $5 \%$ non-fat milk (Bio-Rad, Hercules, CA, USA) in TBS, and expression of GRP78/BiP and $\beta$-actin in the cell homogenate was detected using specific anti-BiP rabbit monoclonal antibody (C50B12; 3177, Cell Signaling Technology, Boston, MA, USA) and polyclonal goat anti-rabbit IgHRP (P0447, DakoCytomation Denmark A/S) secondary antibody, and anti$\beta$-actin mouse monoclonal antibody (AC-15; ab6276, Abcam) and polyclonal goat anti-mouse Ig-HRP secondary antibody (P0447, DakoCytomation Denmark $A / S)$, respectively. Signals were detected using $E C L$ Western Blotting Detection Reagents (GE Healthcare, Buckinghamshire, UK). Equal loading was verified by monitoring the expression levels of $\beta$-actin.

\section{Gene transfer and Luc assay}

Cells were seeded at $5 \times 10^{4}$ cells per well in 24-well tissue culture plates and allowed to grow overnight. The next day, cells were infected with different multiplicities of infection in triplicate. After incubation at $37^{\circ} \mathrm{C}$ for $1 \mathrm{~h}$, media was removed and fresh media was added. Forty-eight hours later the media was removed, cells were washed one time with PBS, lysed, and Luc activity was determined using the Luciferase Assay System (Promega, Madison, WI, USA) and Femtomaster-FB12 luminometer (Zylux Corp., Oak Ridge, TN, USA) according to the manufacturers' instructions. Luc activity was normalized to the protein concentration of the cell lysate using DC Protein Assay (Bio-Rad) according to the manufacturer's instructions. The results are expressed as relative light units per $5 \times 10^{4}$ cells, and bars represent the mean \pm s.d.

\section{Expression of recombinant Ad5 knob}

The knob domain of Ad5 fiber protein was expressed in E. coli as described previously. ${ }^{18}$ Soluble His-tagged Ad5 knob was purified by gravity-flow affinity chromatography using a Ni-NTA resin (Qiagen). The concentration of the purified protein was determined using DC Protein Assay (Bio-Rad) according to the manufacturer's instructions. The purity of the recombinant protein was monitored by western blotting using anti-His monoclonal antibody (HIS-1, H1029, Sigma) and goat anti-mouse Ig-HRP (P0447, DakoCytomation Denmark A/S).

\section{Competitive inhibition assay}

To block hCAR-specific transduction, D54MG cells were seeded at $1 \times 10^{5}$ cells per well in a 24-well tissue culture plate and incubated after 1 day with $100 \mu \mathrm{g} \mathrm{ml}^{-1}$ of soluble Ad5 knob protein for $1 \mathrm{~h}$ at $4{ }^{\circ} \mathrm{C}$ before infection with $2 \times 10^{3}$ vp per cell of Ad5eGFP or AdGRP78-BPeGFP. Forty-eight hours after infection, eGFP expression was visualized using fluorescence microscopy.

To block GRP78-specific binding, cells were seeded at $1 \times 10^{5}$ cells per well in a 24-well tissue culture plate. AdGRP78-BPLuc and AdFFLuc were incubated with $200 \mathrm{~g} \mathrm{ml}^{-1}$ of recombinant BiP protein (ab176142, Abcam) or BSA at $37^{\circ} \mathrm{C}$ for $30 \mathrm{~min}$. Cells were then washed one time with PBS and infected with Ads at $2 \times 10^{3}$ vp per cell. After incubation for $1 \mathrm{~h}$ at $37^{\circ} \mathrm{C}$, cell culture media was removed, cells were washed with PBS, and fresh media was added. In addition, D54MG cells were preincubated with $50 \mu \mathrm{g} \mathrm{ml}^{-1}$ of BiP/GRP78 rabbit monoclonal antibody (C50B12; 3177, Cell Signaling Technology) or BSA for $1 \mathrm{~h}$ before infection with AdGRP78-BPLuc or AdFFLuc. Cells were then infected with Ads at $2 \times 10^{3}$ vp per cell. After $48 \mathrm{~h}$, cells were washed one time with PBS and lysed. Luc activity was determined as described above.

\section{Animal study}

For in vivo experiments, 4-6-week-old female nude athymic mice were purchased from the Envigo (Indianapolis, IN, USA) and housed under aseptic conditions in microisolator cages, and experiments were carried out according to the protocols approved by the Institutional Animal Care and Use Committee, approved by the Division of Comparative Medicine, School of Medicine, Washington University in St Louis. To establish human tumor xenografts $1 \times 10^{6}$ D54MG cells were injected subcutaneously (s.c.) into both left and right flanks of mice. Following tumor injection, mice were returned to their sterile microisolator cages and maintained on autoclaved lab-chow and sterile water ad libitum. Radiation therapy studies were carried out in s.c. models in which animals were treated with Ad vectors at the time of established tumor growth $\left(\sim 0.5 \mathrm{~cm}^{3}\right)$. Imaging and imaging analysis were performed in the Optical Radiology Laboratory, Mallinckrodt Institute of Radiology, School of Medicine, Siteman Cancer Center, Washington University in St Louis.

\section{Statistical analysis}

In experiments where triplicates were run to reduce measurement error, statistical analyses were conducted on the mean triplicate value. All error terms are expressed as the s.d. of the mean. Significance levels for comparison of differences between groups in the experiments were analyzed using the Student's $t$ - test. All reported $P$-values are two-sided. The differences between groups were considered statistically significant when the $P$-value was $\leqslant 0.05$. 


\section{RESULTS}

Evaluation of GRP78 expression

The expression of GRP78 mRNA was examined using RT-PCR of total mRNA of cells after irradiation. The GAPDH cDNA was used as an internal standard for template loading. PCR products were separated by electrophoresis and the relative abundance of PCR products was semiquantified by densitometry. All tested glioma cells demonstrated a dose-dependent increase of GRP78 gene expression following radiation treatment in comparison with mock-irradiated cells (Figure 1a). On the basis of the results of this initial screening, we used D54MG cells that demonstrated the highest levels of GRP78 expression after irradiation for subsequent experiments.

To evaluate GRP78 protein expression following XRT, D54MG cells were irradiated at $3 \mathrm{~Gy}, 6 \mathrm{~Gy}$, three times at $3 \mathrm{~Gy}$, or mock irradiated. Twenty-four hours after the last radiation treatment cell lysates were subjected to western blotting analysis. As shown in Figure 1b, expression of GRP78 mRNA in D54MG cells was associated with a dose-dependent increase in the levels of GRP78 protein expression following radiation treatment. As seen in Figure 1c, there was a time-dependent increase in GRP78 protein expression following intermediate dose of XRT at $6 \mathrm{~Gy}$, which was evident at $6 \mathrm{~h}$, and reached a peak expression 24-48 h after radiation treatment. Similar results were obtained with other glioma cells (data not shown).

To investigate whether XRT can increase GRP78 expression on the cell surface, D54MG cells were irradiated with a single dose of 6 Gy XRT, harvested at different time points after irradiation and subjected to flow cytometric assay (Figure 1d). As can be seen from the overlay histograms, $\sim 60-65 \%$ of cells were positive for surface GRP78 expression at time points $0,1,6$ and $18 \mathrm{~h}$ after irradiation. Slight increase in the percentage of positive cells (73.1\%) was observed at $24 \mathrm{~h}$. The highest level of GRP78 surface expression was observed at $48 \mathrm{~h}$ after radiation treatment $(90.4 \%)$. D54MG cells were also irradiated with three fractions of $3 \mathrm{~Gy}$ over a course of $24 \mathrm{~h}$ and harvested $24 \mathrm{~h}$ after the last XRT (Figure 1e). We observed a higher induction of GRP78 surface expression $(96.6 \%)$ with fractionated XRT at an earlier time point (24 h) as compared with the single dose of $6 \mathrm{~Gy}$. Therefore, all further experiments were performed with three fractions of $3 \mathrm{~Gy}$ irradiation.

In addition, D54MG cells were irradiated three times at 3 or $0 \mathrm{~Gy}$ and subjected to immunocytochemistry analysis at $24 \mathrm{~h}$ after the last radiation treatment. As illustrated in Figure $1 \mathrm{f}$, immunocytochemistry analysis revealed an increasing number of stained D54MG cells (shown in brown diaminobenzidine tetrahydrochloride biding color on the cell membrane) irradiated three times at $3 \mathrm{~Gy}$ in comparison with mock-irradiated cells. There was no signal observed using normal mouse IgG and secondary antibody controls.

Rescue and validation of Ad vectors incorporating binding peptides

For this study, we developed a panel of recombinant replicationincompetent Ad5-based vectors expressing the firefly Luc or eGFP gene under transcriptional control of the human cytomegalovirus major immediate-early enhancer/promoter element. A simplified schematic diagram of recombinant Ad genomes used in this study is presented in Table 2. To develop AdGRP78-BPLuc and AdGRP78BPeGFP recombinant Ads the chimeric fiber-fibritin protein-coding DNA containing the entire Ad5 fiber shaft fused to the 12th coiledcoil (foldon) trimerizing domain of bacteriophage T4 followed by a 3x(GGGGS) peptide linker connected to a KKKGGGGIRLRG peptide. Vectors expressing chimeric fiber-fibritin (AdFFLuc) and wild-type Ad5 fiber (Ad5Luc and Ad5eGFP) were used as isogenic controls and as wild-type control Ad vectors, respectively.
PCR analysis was used to demonstrate the incorporation of the chimeric fiber-fibritin gene region in the Ad genome. The PCR was performed using Ad5-specific primers, which anneal at $100 \mathrm{bp}$ upstream and downstream of the fiber gene, and purified AdGRP78-BPeGFP, Ad5Luc, Ad5eGFP, AdGRP78-BPLuc and AdFFLuc viral genome DNA as templates. As shown in Figure 2a, the PCR analysis demonstrated the amplification of the corresponding fiber region in each of the Ads.

To demonstrate the incorporation of the targeting fiber-fibritin fusion proteins into the virus particle, $5 \times 10^{9} \mathrm{vp}$ of boiled and unboiled purified Ads were loaded in each lane and subjected to SDS-PAGE followed by western blotting analysis using antifiber monoclonal antibody. The predicted molecular weight of fiber monomers is $61.6 \mathrm{kDa}$ for Ad5Luc and $52.7 \mathrm{kDa}$ for vectors encoding chimeric fiber-fibritin proteins. As illustrated in Figure $2 \mathrm{~b}$, genetic incorporation of binding peptides into fiberfibritin produced stable fusion with fiber-fibritin molecules that maintained the trimerization potential of fiber-fibritin chimeric proteins under native conditions.

For initial determination of transduction efficiency and specificity of fiber-modified Ad, human glioma D54MG, U87MG and U251MG cells were irradiated three times at $3 \mathrm{~Gy}$ over $24 \mathrm{~h}$ and then infected with Ad5eGFP or AdGRP78-BPeGFP recombinant Ads. Fluorescence microscopy was performed $48 \mathrm{~h}$ after infection using an Olympus IX70 inverted fluorescence microscope (Tokyo, Japan). All samples were analyzed in a blinded manner, and images shown are representative of three wells per group with the experiment performed three times. As shown in Figure 2c, GIRLRG peptides fused to fiber-fibritin provided retargeting of $\mathrm{Ad}$ mediated eGFP gene transfer of irradiated cancer cells. These results correlated with GRP78 expression in the human glioma cell lines.

XRT induction of neoantigens allows enhanced gene transfer in glioma cells via fiber-modified Ads

To confirm that fiber modifications resulted in Ad retargeting, human glioma cells were irradiated three times at $3 \mathrm{~Gy}$ over $24 \mathrm{~h}$ and infected with AdGRP78-BPLuc. AdFFLuc vector expressing fiber-fibritin and Ad5Luc displaying a wild-type Ad5 fiber was used as an isogenic control and wild-type control Ad vector, respectively. The level of Luc reporter gene expression was measured $48 \mathrm{~h}$ after infection. The relative levels of Luc expression in glioma cells were assessed by determining the ratio of Luc activity in irradiated cells to that in mock-irradiated cells. For each cell line, three independent experiments were carried out in triplicate cultures and normalized for protein. Statistical analyses were conducted on the mean triplicate value from each experiment. Before XRT, the mean Luc reporter gene expression at baseline in all cell lines was not significantly different between treatment groups $(P>0.05)$, and the within-treatment variances were not significantly different $(P>0.05)$. As shown in Figure 3a, gene transfer efficiency of Ad5Luc and AdFFLuc was not significantly altered following irradiation of glioma cells. In contrast, gene transfer efficiency of AdGRP78-BPLuc was increased following XRT in all tested cells. The AdGRP78-BPLuc-infected D54MG cells had greater relative Luc expression after irradiation than did U87MG or U251MG cells (interaction $P$-value $=0.05$ ). For the D54MG cell line, there was significantly greater Luc expression in cells infected with AdGRP78-BPLuc following XRT, versus mock-irradiated cells $(P$-value $<0.05)$, but no significant difference between those cells infected with Ad5Luc or AdFFLuc $(P$-value $=0.2)$.

Next, we evaluated the Luc activity in D54MG cells following XRT using different doses of radiation (Figure $3 \mathrm{~b}$ ). This doseescalation study demonstrated a dose-dependent increase in XRT/ mock ratios of Luc expression in AdGRP78-BPLuc-infected cells. There were significant differences across the doses of radiation for 
a

GAPDH

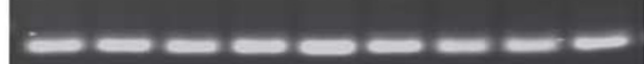

b

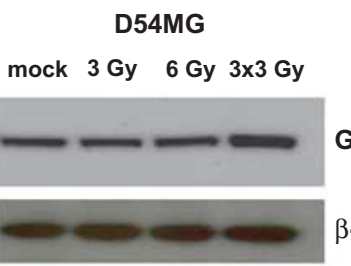

$\mathbf{O h}$
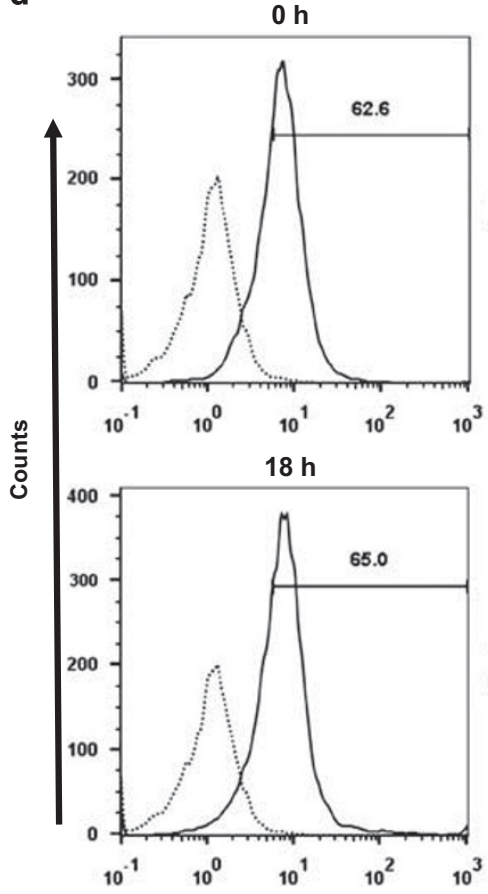

c

GRP78 (72 kDa)

$\beta$-actin (45 kDa)

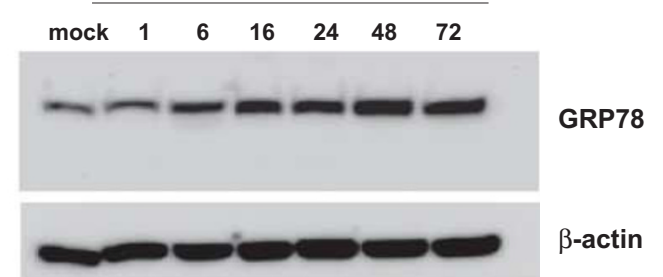

$1 \mathrm{~h}$

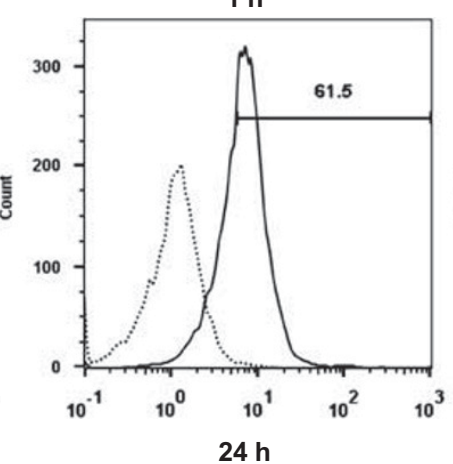

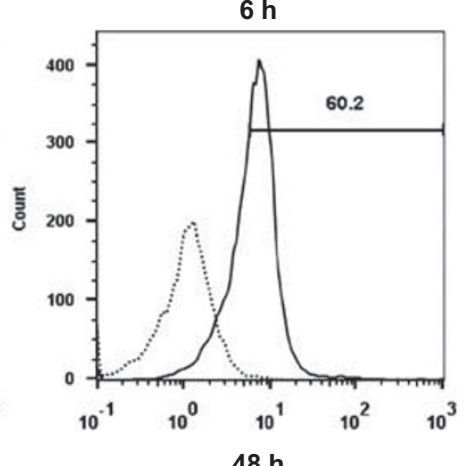
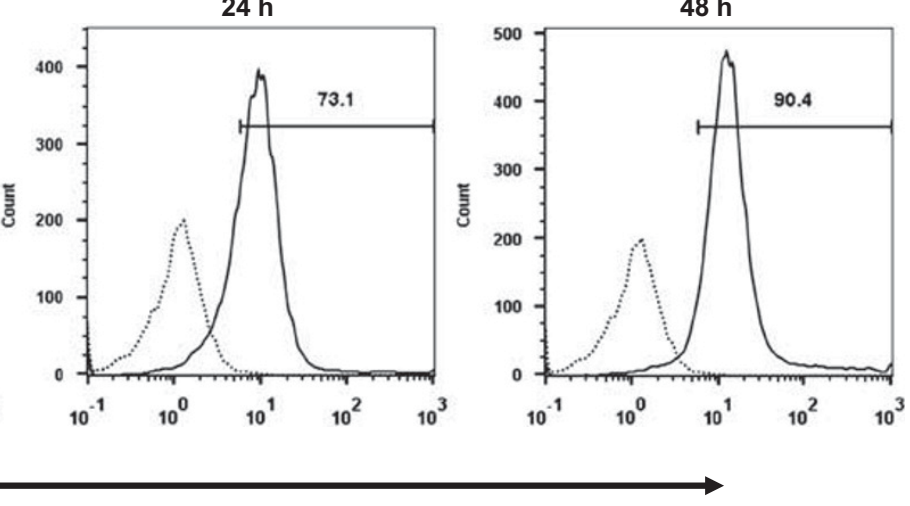

Alexa Flour 488

Figure 1. Evaluation of GRP78 expression. (a) The level of GRP78 mRNA expression was determined by RT-PCR. Human glioma cells were irradiated at $3 \mathrm{~Gy}(3 \mathrm{~Gy})$, three times at $3 \mathrm{~Gy}(3 \times 3 \mathrm{~Gy})$, or untreated (mock), and total RNA was extracted; the first-strand cDNA was synthesized using random hexamer primers and used as the template for PCR. GAPDH CDNA was used as an internal standard. Products of PCR were analyzed by $0.6 \%$ agarose electrophoresis with ethidium bromide staining. One representative of two different experiments is shown. (b) Evaluation of GRP78 protein expression following XRT. D54MG cells were irradiated at 3 Gy, 6 Gy, three times at 3 Gy (3×3 Gy) or mock irradiated. Cells were collected $24 \mathrm{~h}$ after the last radiation treatment and equal volumes of cell lysates were loaded in each lane with boiling in a sample buffer, separated on SDS-PAGE, followed by transfer to a PVDF membrane and western blotting analysis using anti-GRP78/BiP antibody. One representative of two different experiments is shown. (c) D54MG cells were irradiated at 6 Gy or mock irradiated, collected at different time points after radiation treatment, and equal volumes of cell lysates were loaded in each lane with boiling in a sample buffer and separated on SDS-PAGE followed by transfer to a PVDF membrane and western blotting analysis using specific anti-GRP78/BiP antibody. The human actin protein was used as a loading control. One representative of three different experiments is shown. (d) Evaluation of surface expression of GRP78 using flow cytometric analysis. D54MG glioma cells were irradiated with a single dose at 6 Gy and harvested at the indicated time points after XRT. Highest surface expression of GRP78 was observed $48 \mathrm{~h}$ after irradiation. (e) D54MG cells were irradiated three times at $3 \mathrm{~Gy}$ over $24 \mathrm{~h}$ and harvested at $24 \mathrm{~h}$ post irradiation. Overlay histograms show increased surface expression of GRP78 after irradiation. The broken line indicates isotype control antibody and the solid line indicates anti-GRP78 antibody. (f) Evaluation of GRP78 expression on the cell surface using immunocytochemistry analysis. D54MG cells were irradiated three times at 3 Gy or 0 Gy. Examination of DAB-stained cells showed that irradiation increased the number of GRP78-positive (brown-stained) cells compared with mock-irradiated cells. CDNA, complimentary DNA; DAB, diaminobenzidine tetrahydrochloride; GAPDH, glyceraldehyde 3-phosphate dehydrogenase; GRP78, glucose-regulated protein 78; PVDF, polyvinylidene difluoride; RT-PCR, reverse transcriptase PCR; XRT, radiotherapy. 
e

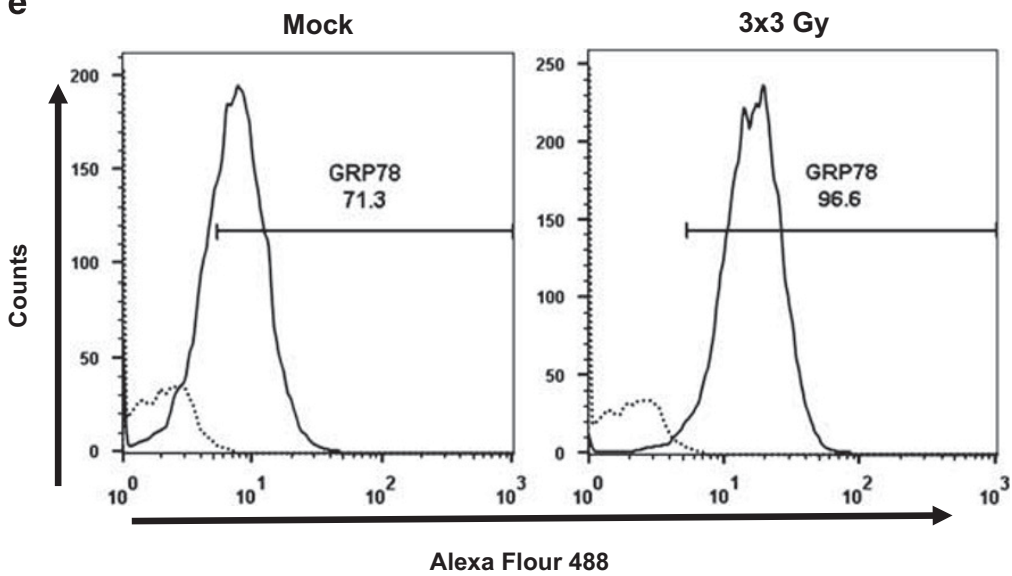

f

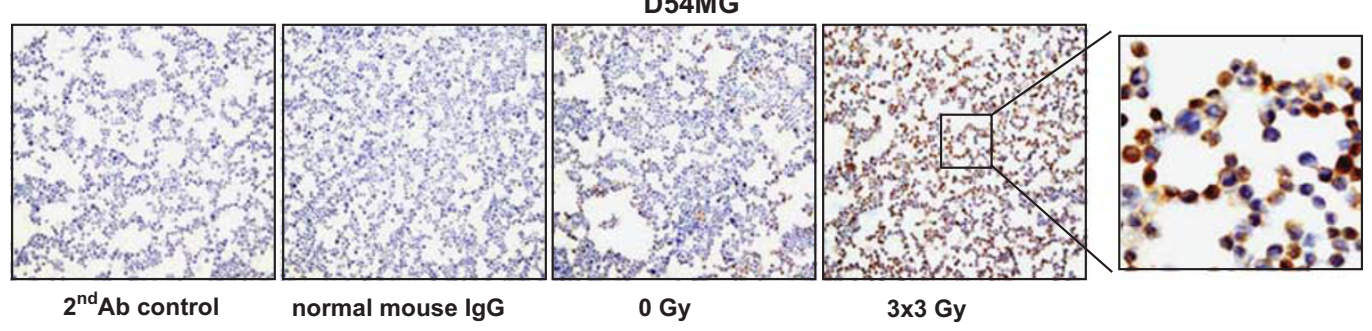

Figure 1. Continued.

Table 2. Schematic diagram of the Ad vectors used in this study

\begin{tabular}{|c|c|c|c|}
\hline Vector & $\begin{array}{l}\text { Reporter } \\
\text { gene }\end{array}$ & Fiber protein & Target \\
\hline Ad5Luc & Luc & Wild-type Ad5 & CAR \\
\hline Ad5eGFP & eGFP & Wild-type Ad5 & CAR \\
\hline AdGRP78-BPeGFP & eGFP & KKKGGGGIRLRG & GRP78 \\
\hline AdGRP78-BPLuc & Luc & KKKGGGGIRLRG & GRP78 \\
\hline AdFFLuc & Luc & $\begin{array}{l}\text { Fiber-fibritin } \\
\text { (no binding domain) }\end{array}$ & NA \\
\hline
\end{tabular}

Abbreviations: Ad, adenovirus; eGFP, enhanced green fluorescent protein; GFP, green fluorescent protein; GRP78, glucose-regulated protein 78; Luc, luciferase; NA, not applicable. Genomic regions relevant to our studies are shown.

D54MG cells infected with AdGRP78-BPLuc ( $P$-value $<0.05)$, but no significant differences between cells infected with Ad5Luc or AdFFLuc $(P$-value $=0.1)$.

Ad transduction efficiency to human glioma cells is highly variable, and gene transfer levels correlate directly with the level of expression of the primary receptor for Ad on the cell surface. Thus, low levels of expression of CAR in most tumor cells may be a major limiting factor for the success of Ad5-based gene therapy. We evaluated whether a modification in the Ad fiber resulted in the ability of fiber-modified Ads to achieve CAR-independent binding and infection in vitro. As previous studies demonstrated the ability of recombinant Ad5 knob to block binding of the corresponding Ad5 vectors or recombinant fiber protein to its receptor, ${ }^{18}$ we expressed recombinant Ad5 knob and determined the purity of the recombinant proteins by western blotting with anti-His monoclonal antibody (data not shown). The expression of av $\beta 3 / \operatorname{av} \beta 5$ integrins and CAR on the surface of human cancer cells was examined using FACS (Table 3). As shown in Figure 3c, preincubation with Ad5 knob did not inhibit the AdGRP78BPeGFP-mediated eGFP expression in D54MG cells. In contrast, Ad5eGFP infection was efficiently inhibited by recombinant Ad5 knob in proportion to protein concentrations (results not shown).

To confirm the specificity of AdGRP78-BPLuc infection we evaluated GRP78/BiP-mediated inhibition of Luc gene transfer. For this study, AdGRP78-BPLuc or AdFFLuc was preincubated with GRP78/BiP recombinant protein for $1 \mathrm{~h}$ before infection of D54MG cells. Incubation of AdGRP78-BPLuc with BSA was used as control. In addition, D54MG cells were preincubated with BiP/GRP78 rabbit monoclonal antibody or BSA for $1 \mathrm{~h}$ before infection with Ads. Forty-eight hours after infection, Luc activity was measured (Figure 3d). Gene transfer efficiency of AdGRP78-BPLuc was significantly reduced after incubation with blocking proteins, and only $\sim 40 \%$ of Luc expression was retained following infection with AdGRP78-BPLuc, and $~ 49 \%$ after incubation of D54MG cells with anti-BiP/GRP78 monoclonal antibody ( $P$-value $<0.05)$. Results of a gene transfer blocking assay demonstrated inhibition of Luc gene transfer in D54MG cells following pretreatment of fibermodified Ads with blocking protein in a dose-dependent manner (data not shown).

In vivo analysis of Ad vector targeting to XRT-induced neoantigens Initially, we investigated whether modifications of Ad fiber protein alter Ad in vivo selectivity for XRT-induced neoantigen, subsequent to Ad-mediated gene transfer. To evaluate Ad-mediated eGFP expression in vivo, mice bearing D54MG human tumor xenografts $(n=3)$ were irradiated three times at $3 \mathrm{~Gy}$ over $24 \mathrm{~h}$ in the right flank, then injected i.t. in both sites with AdGRP78BPeGFP, and eGFP expression was evaluated at different time points after injection. As illustrated in representative optical images (Figure 4a), eGFP expression was detected in tumors injected with AdGRP78-BPeGFP as early as $24 \mathrm{~h}$ after injection and 
reached a peak at 3-7 days post injection. Results of fluorescence imaging analysis of eGFP expression in irradiated and mockirradiated xenografts on individual D54MG tumor-bearing mice are summarized in Figure $4 \mathrm{~b}$. There was increasing eGFP expression (XRT/mock ratios) following AdGRP78-BPeGFP injection in the irradiated xenografts in comparison with mock-treated tumors (Figure 4c). Despite high levels of eGFP expression in D54MG tumors following XRT, immunohistochemical analysis revealed no difference in the biodistribution of eGFP expression in a cross-section of tumor from mice following local administration of AdGRP78-BPeGFP in comparison with Ad5eGFP injection (data not shown).

To evaluate Ad-mediated Luc expression in vivo, mice bearing D54MG human tumor xenografts were irradiated three times at
$3 \mathrm{~Gy}$ over $24 \mathrm{~h}$ in the right flank, and then were randomly divided into groups $(n=4-5)$ receiving $1 \times 10^{10} \mathrm{vp}$ per tumor of AdGRP78BPLuc or Ad5Luc. Tumors were collected at 3 days after administration of AdGRP78-BPLuc or Ad5Luc, and the levels of Luc expression were determined. Results of Luc expression assay in irradiated and mock-irradiated D54MG tumors are summarized in Figure $4 \mathrm{~d}$. To quantify the relative levels of Luc expression we used the irradiated-to-mock-irradiated (XRT/mock) ratios of Luc activity in tumors. Irradiated-to-mock-irradiated ratios were calculated for each animal with the relative light units normalized by the protein concentration of the tumor tissue lysate. As shown in Figure $4 \mathrm{e}$, the XRT-to-mock-irradiated ratio of Luc expression was increased 18-fold for tumors injected with AdGRP78-BPLuc, in comparison with mice injected with Ad5Luc.
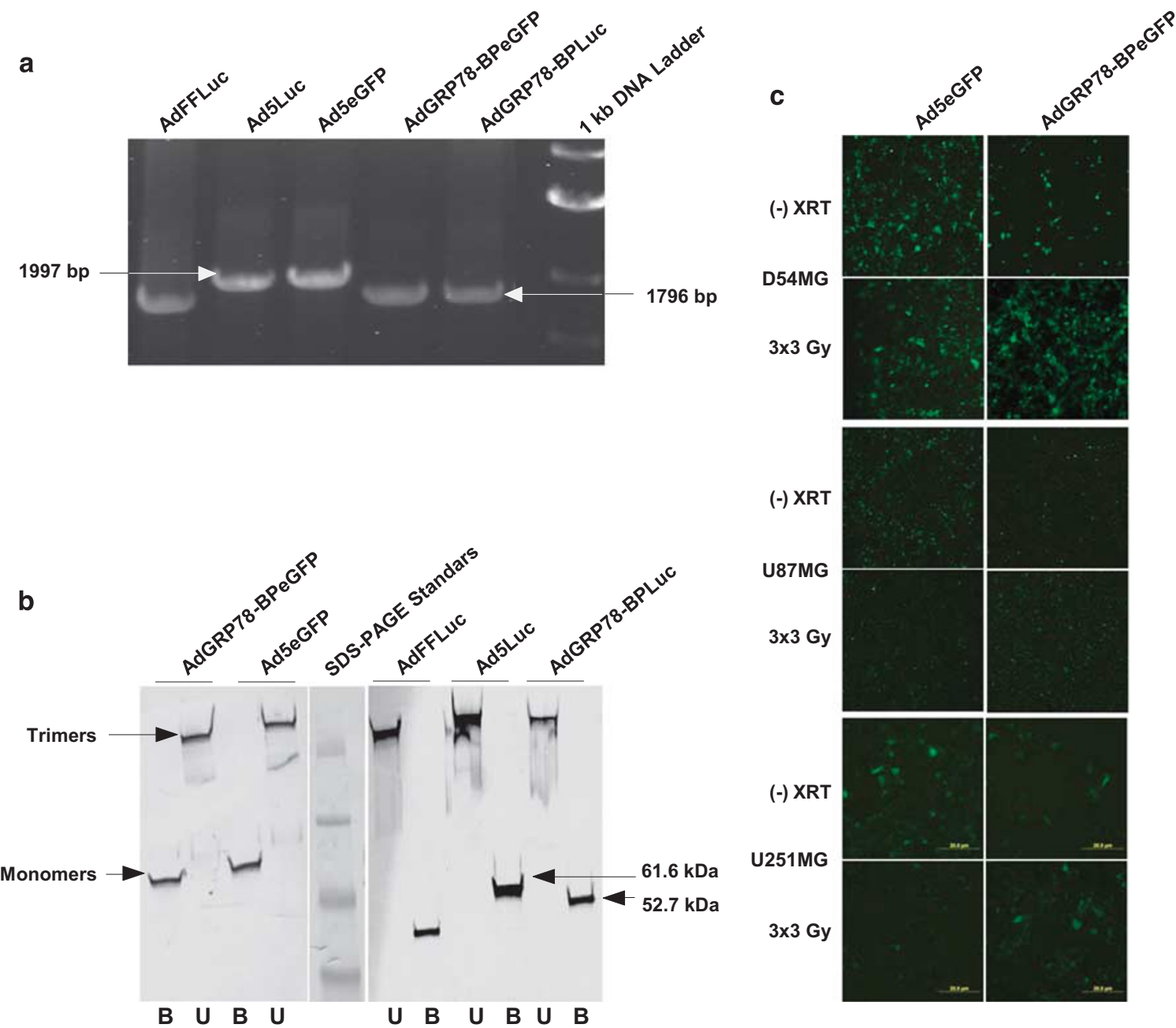

Figure 2. Validation of genetic incorporation of GRP78-binding peptides into fiber-fibritin and Ad targeting to XRT-induced neoantigens. (a) Validation of genetic incorporation of binding peptides into fiber-fibritin using PCR. Viral genomic DNA was extracted from purified viral stock and subjected to PCR analysis. PCR products were analyzed by means of $0.6 \%$ agarose electrophoresis with ethidium bromide staining. L, $1 \mathrm{~kb}$ DNA Ladder. One representative of two different experiments is shown. (b) Assessment of incorporation of fiber-fibritin proteins with binding peptide into Ad particles using western blotting analysis. Equal amounts $\left(5 \times 10^{9} \mathrm{vp}\right)$ of purified Ads were loaded into each lane with boiling in a sample buffer (B) or without boiling (U) and separated on SDS-PAGE followed by transfer to a PVDF membrane. Fiber protein expression was detected using anti-fiber monoclonal antibody. One representative of two different experiments is shown. (c) Adenoviral vector targeting to XRT-induced neoantigens - in vitro eGFP expression. For initial determination of transduction efficiency and specificity of Ad-mediated eGFP expression, human glioma cells were irradiated three times at 3 Gy over $24 \mathrm{~h}(3 \times 3 \mathrm{~Gy})$ or mock treated ('-' XRT) and then infected with $1 \times 10^{3} \mathrm{vp}$ per cell of AdGRP78-BPeGFP or Ad5eGFP recombinant Ads. Forty-eight hours after infection, cellular eGFP expression was visualized using fluorescence microscopy. One representative of three different experiments is shown. Ad, adenovirus; eGFP, enhanced green fluorescent protein; GFP, green fluorescent protein; GRP78, glucose-regulated protein 78; PVDF, polyvinylidene difluoride; VP, viral particles; XRT, radiotherapy. 


\section{a}

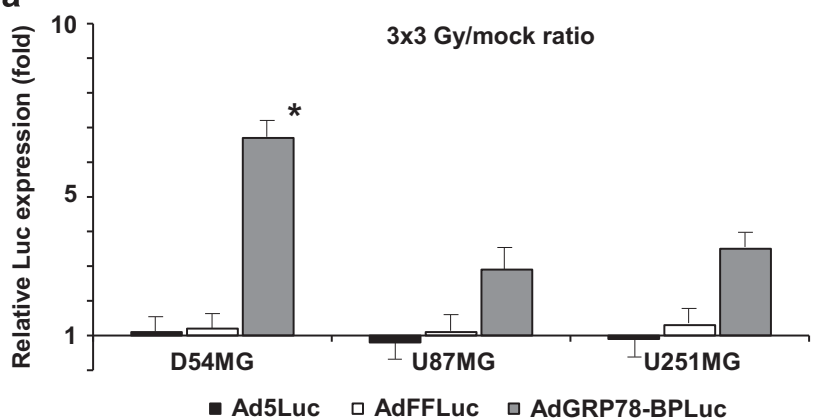

C

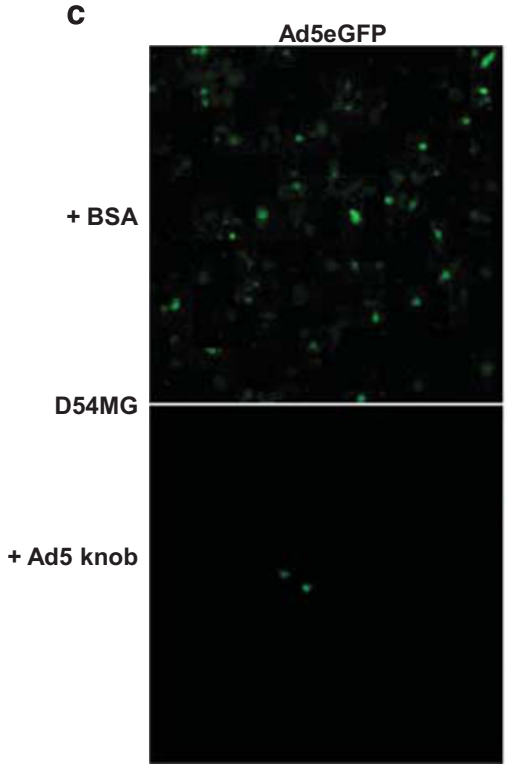

AdGRP78-BPeGFP

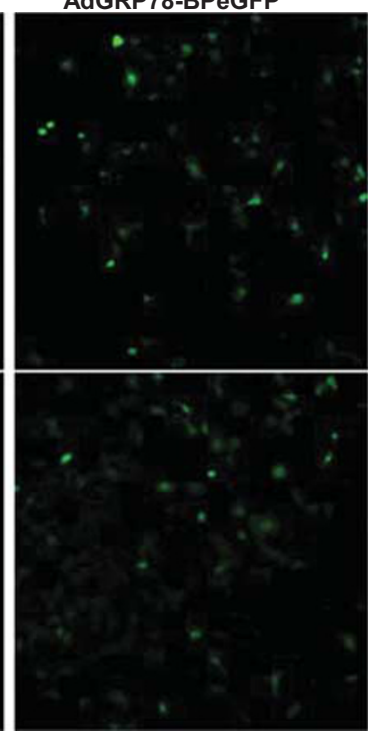

b

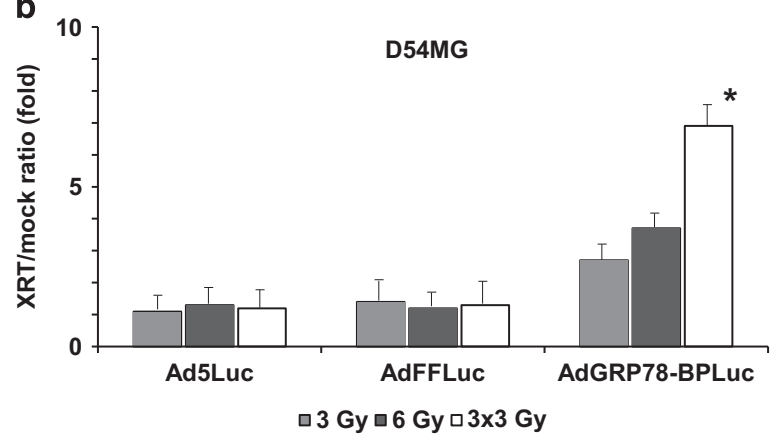

d

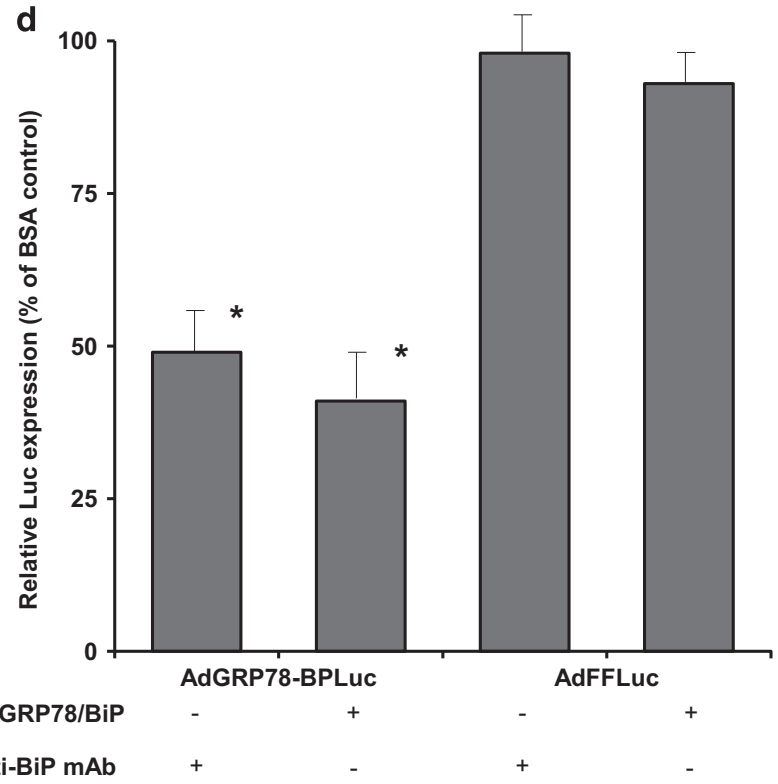

Figure 3. XRT induction of neoantigens allows enhanced gene transfer into human glioma cells via fiber-modified Ads. (a) Evaluation of the efficacy and specificity of the XRT-induced neoantigen-targeted gene transfer. Glioma cells were irradiated three times at $3 \mathrm{~Gy}$ over $24 \mathrm{~h}$ and infected with AdGRP78-BPLuc, AdFFLuc or Ad5Luc vector. Luc activity was detected in the lysates of infected cells at $48 \mathrm{~h}$ after infection. Data are presented as the irradiated-to-mock-irradiated ratio of Luc activity, and bars represent the mean \pm s.d. of three independent experiments, each performed in three replicates $(*, P<0.05$; versus mock). (b) Dose-dependent targeting of adenoviral vectors to XRT-induced neoantigens. D54MG cells were irradiated at $3 \mathrm{~Gy}, 6 \mathrm{~Gy}$, three times at $3 \mathrm{~Gy}$, or mock irradiated, and then infected with AdGRP78-BPLuc, AdFFLuc or Ad5Luc. Luc activity was monitored in the cell lysates at $48 \mathrm{~h}$ post infection. Data are presented as the irradiated-to-mock-irradiated ratio of Luc activity, and bars represent the mean \pm s.d. of three independent experiments, each performed in three replicates ${ }^{*}, P<0.05$; versus mock). (c) Validation of hCAR-independent infection. For competition blocking assay, D54MG cells were preincubated with soluble Ad5 knob protein or BSA and infected with $2 \times 10^{3}$ vp per cell of Ad5eGFP or AdGRP78-BPeGFP recombinant Ads. Forty-eight hours after infection, eGFP expression was visualized using fluorescence microscopy. One representative of three different experiments is shown. (d) Validation of target specificity for XRT-induced neoantigens targeting. AdGRP78-BPLuc and AdFFLuc were preincubated with GRP78/BiP or BSA; D54MG cells were infected with Ads at $2 \times 10^{3}$ vp per cell. In addition, D54MG cells were incubated with anti-GRP78/BiP monoclonal antibody (anti-BiP mAb) or with BSA for $1 \mathrm{~h}$ and infected with Ads at $2 \times 10^{3}$ vp per cell. Luc activity was detected in the cell lysates at $48 \mathrm{~h}$ post infection. Relative Luc expression is given as a percentage of the Luc activity of BSA-treated samples. Data are presented as mean \pm s.d. of three independent experiments, each performed in three replicates $(*, P<0.05$ versus BSA). Ad, adenovirus; BSA, bovine serum albumin; eGFP, enhanced green fluorescent protein; GFP, green fluorescent protein; GRP78, glucose-regulated protein 78; Luc, luciferase; VP, viral particles; XRT, radiotherapy.

\section{DISCUSSION}

Glioblastoma multiforme is one of the most aggressive types of malignancies with very high mortality. The existing treatment options consist of surgery and radiation therapy in combination with temozolomide and have far fallen short of breakthrough success. ${ }^{19-21}$ Malignant gliomas are known to invade the surrounding normal brain tissue, which results in incomplete surgical resection and high incidence of recurrence. Gliomas have a dismal median overall survival of about 15 months. ${ }^{22}$ Thus, it is imperative to exploit new therapeutic approaches to improve the clinical outcome of this disease. The reason for this poor response to radiation treatment is believed to be dependent on a subset of tumor cells exhibiting XRT resistance. Thus, development of an effective therapy for the treatment of gliomas is predicated on efficiently targeting XRT-resistant tumor cells. In order to overcome XRT resistance, strategies involving a combination of radiation therapy and gene therapy have been extensively investigated. A growing body of evidence demonstrates the promise of gene therapy in preclinical and early clinical studies. ${ }^{23,24}$ Gene delivery techniques to the brain have been generally based on the direct injection of the gene therapy vector into the tumor mass or into the surgical cavity margin after tumor debulking.

XRT, as a part of standard therapy for glioma, consisted of fractionated focal irradiation at a dose of $2 \mathrm{~Gy}$ per fraction for a total dose of $60 \mathrm{~Gy}$ alone or in combination with chemotherapy. ${ }^{25}$ 
Table 3. Flow cytometric analysis of $\alpha \mathrm{v} \beta 3$ and $\alpha \mathrm{v} \beta 5$ integrins and CAR surface expression

\begin{tabular}{lccc}
\hline Cell line & \multicolumn{3}{c}{ \% of positive cells (mean of fluorescence intensity) } \\
\cline { 2 - 4 } & \multicolumn{1}{c}{$\operatorname{av} \beta 3$} & \multicolumn{1}{c}{$\operatorname{av} \beta 5$} & CAR \\
\hline U251MG & $26 \pm 4(22 \pm 9)$ & $94 \pm 6(63 \pm 10)$ & $55 \pm 7(101 \pm 11)$ \\
U373MG & $86 \pm 6(60 \pm 14)$ & $90 \pm 7(55 \pm 6)$ & $32 \pm 4(37 \pm 6)$ \\
U87MG & $42 \pm 4(46 \pm 7)$ & $83 \pm 8(53 \pm 12)$ & $12 \pm 2(14 \pm 5)$ \\
D54MG & $90 \pm 8(66 \pm 9)$ & $91 \pm 6(57 \pm 11)$ & $37 \pm 4(49 \pm 5)$ \\
HEK293 & $89 \pm 10(87 \pm 12)$ & $92 \pm 7(94 \pm 20)$ & $96 \pm 8(76 \pm 6)$ \\
\hline
\end{tabular}

Abbreviation: FACS, fluorescence-activated cell sorter. ${ }^{\text {a Human cancer cells }}$ were stained with saturating amounts of monoclonal antibodies recognizing $\alpha v \beta 3, \alpha v \beta 5$ or hCAR, and expression was evaluated by FACS analysis. A negative immunoglobulin $\mathrm{G}$ isotype primary mouse antibody was used as a control. Data are the means \pm s.d. of three independent experiments.

It is now well known that exposure of tumor cells to clinically relevant doses of XRT triggers a large network of intracellular signaling pathways that collectively produce a multilayered biological response and eventually can result in the development of XRT resistance. Over the past decade, it has been shown that XRT produces overexpression of $\mathrm{GRP} 78 / \mathrm{BiP}^{11}$ on the cell membrane. We have earlier evaluated GRP78 expression at various doses of XRT at different time points after irradiation. ${ }^{26}$ We observed that expression of GRP78 is dose and time dependent. The maximum expression of GRP78 was observed at $72 \mathrm{~h}$ after XRT at $6 \mathrm{~Gy}{ }^{26}$ In this study, GRP78 expression was analyzed using immunocytochemistry and flow cytometric assay. These two methods are complementary in their representation of GRP78 expression on the cell surface, with immunostaining allowing clear identification of cell surface expression and flow cytometry allowing for sensitive quantification of GRP78 protein expression. These studies have confirmed higher induction of GRP78 surface expression after fractionated XRT at an earlier time point $(24 \mathrm{~h})$ in comparison with the single dose of $6 \mathrm{~Gy}$.

Phage-display peptide biopanning has been successfully used to identify GIRLRG peptides targeting XRT-inducible neoantigen GRP78/BiP. ${ }^{11}$ GRP78/BiP is a member of the Hsp70 superfamily of chaperones and under physiological conditions localizes mainly in the endoplasmic reticulum. ${ }^{27,28} \mathrm{~A}$ growing body of evidence suggests that GRP78/BiP has a key role in the unfolded protein response via transport of proteins across the endoplasmic reticulum membrane that are involved in regulation of tumor progression, proliferation, angiogenesis, autophagy and apoptosis. ${ }^{12,13,29,30}$ There is increasing evidence that GRP78/BiP overexpression is associated with resistance to therapeutic agents in several tumor types. ${ }^{31}$ Importantly, GRP78/BiP relocation to the cell membrane in response to endoplasmic reticulum stress has been associated with cell transformation and development of drug resistance. ${ }^{32,33}$ Thus, the discovery of this radiation-inducible antigen clearly suggests that the cellular responses to XRT can be explored for retargeting of Ad-mediated therapeutic gene delivery to tumors.

In this study, we evaluated the utility of employing a peptide recognizing an XRT-induced neoantigen for targeting of Admediated gene delivery. To develop XRT-targeted recombinant Ad5-based vectors, we genetically incorporated the GIRLRG peptide that binds specifically to GRP78/BiP into the C-terminus of de-knobbed fiber-fibritin chimera protein comprising the entire Ad5 fiber shaft fused to the foldon of bacteriophage T4 fibritin. Initial evaluation of recombinant Ad vectors demonstrated that genetic incorporation of fiber-fibritin-GRP78-binding peptide resulted in expression of trimeric fusion protein molecules on the surface of Ad particles. We found that targeting peptides employed in this study did not disrupt the trimerization capability of the Ad fiber, and antigen recognition of the GRP78-binding peptide was retained. In addition, we demonstrated the ability of the GIRLRG peptide fused to fiber-fibritin chimera to provide specific and efficient targeting of irradiated cancer cells for Ad-mediated gene transfer.

Although biodistribution study revealed that the absolute levels of reporter gene expression following injection of Ad5Luc with wild-type fiber in the human D54MG tumor remain higher in comparison with fiber-modified Ad vector, the utilization of the GRP78-binding peptide in Ad fiber rather than the wild-type Ad5 fiber produced a significant increase in reporter gene expression in the irradiated xenografts in comparison with the mock-treated tumors. In addition, GRP78-targeted Ad vectors provide an additional level of tumor specificity via circumvention of CAR deficiency of low-CAR/high-GRP78 cancer cells and abolishment of Ad transduction to high-CAR-expressing normal cells. However, the performance of radiation-guided Ad used in this study has been suboptimal because of high basal levels of GRP78 expression in un-irradiated glioma cells. As only a subset of patients may have tumors that are efficiently infected by Ads with wild-type fiber upon intralesional injection, the utilization of radiation-guided Ad vectors, including conditionally replicative oncolytic Ads, by expression of XRT-induced neoantigen targeting ligands in the fiber may prove extremely useful in producing maximum benefit from combination of XRT and Ad-based gene therapy.

Thus, low-dose irradiation of tumor tissue can be harnessed to improve binding and transfer of fiber-modified Ad vectors to XRT-induced neoantigens in tumor tissue and subsequently produce therapeutic gene expression. The combination of gene therapy and XRT could improve the outcome of cancer treatment. A broad range of different gene therapy approaches, including cytolytic and corrective gene therapy, have been successfully applied for experimental therapy in combination with XRT in animal models, with translation into early clinical trials. ${ }^{34}$ This would provide the possibility of utilizing multiple targeting approaches for combined gene therapy and XRT modalities.

Gene therapy strategies offer the potential for specific targeting at several levels, including transcriptional and transductional targeting. Transcriptional targeting is based on employment of both cis-acting and trans-acting elements. The cis-acting components include promoters as well as enhancer regions that also regulate expression of a particular gene. The trans-acting elements belong to a growing group of transcription factors that bind to specific sites within the promoter and/or enhancer regions. On this basis, a number of groups, including ours, demonstrated that expression of radiation-inducible genes such as cytokines and growth factors (for example, early growth factor- 1$)^{35}$ as well as immediate-early genes encoding transcription factors (for example, Fos, Jun, AP-, and NF-KB) is variable and cell dependent. ${ }^{36,37}$ Activated immediate-early genes interact with the promoter region of the so-called late-responding genes, coding for cytokines, involved in the inflammation process (for example, IL-6), and growth factors, involved in cell survival (for example, TGF $\beta 1$, TNF-a). ${ }^{38-40}$ Thus, the promoters from many stress response genes related to cellular fate following DNA damage are potential candidates for cancer gene therapy. At present, several radiationinducible promoters including Egr- $1,{ }^{41-43}$ tPA $^{44}$ p21/WAF- $1^{45}$ and GADD $45 a^{46,47}$ were used for gene delivery in combination with radiation therapy strategies.

Results of in vitro and animal studies demonstrated that transductional control of gene expression using the genetically incorporated GIRLRG peptide that is responsive to ionizing radiation provides an attractive approach for combination radiation therapy and gene therapy against the radiation/chemoresistant subset of GRP78-overexpressed tumor cells. In addition, the search for methods to introduce genes into malignant brain tumor cells led to many advances in the development of cytoreductive gene therapy strategies such as oncolytic virotherapy. ${ }^{48}$ Virotherapy 
a

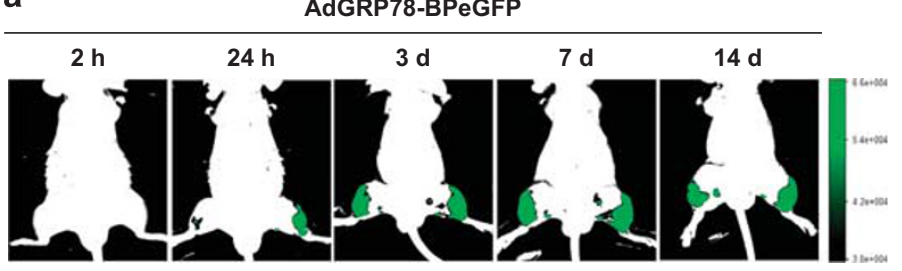

b

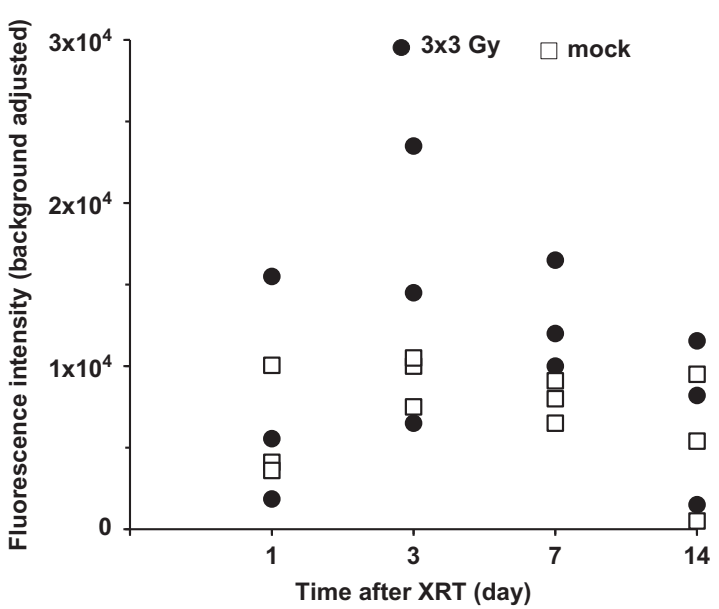

C

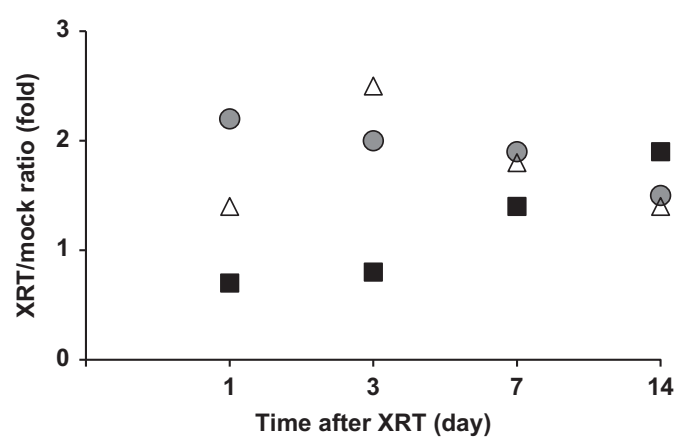

d
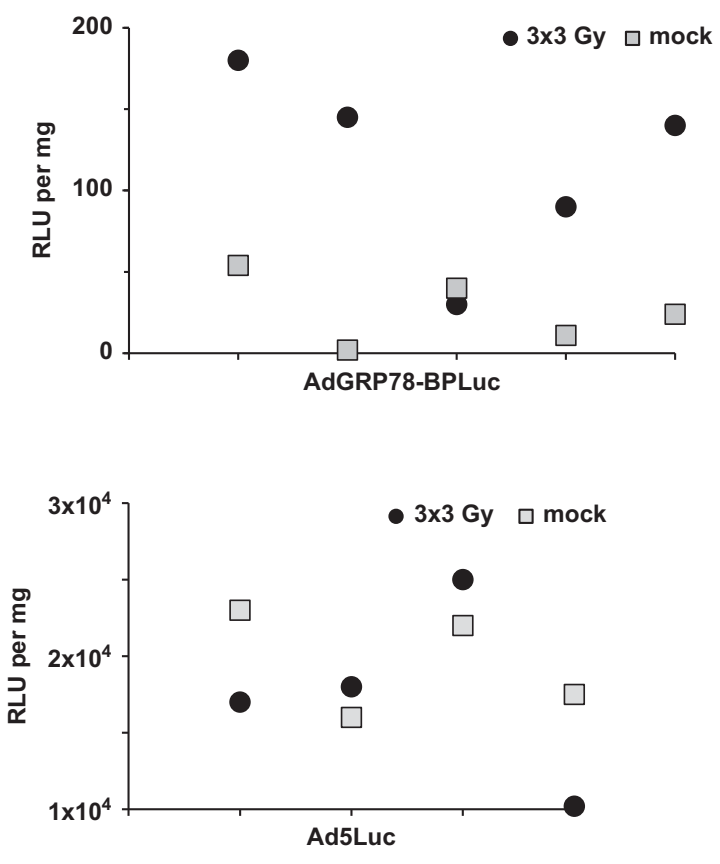

e

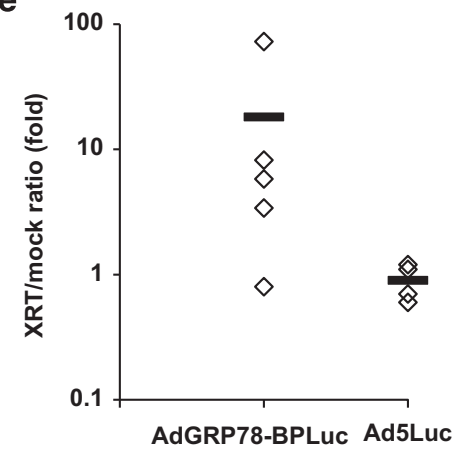

Figure 4. Adenoviral vector targeting XRT-induced neoantigens-in vivo analysis. (a) Human glioma D54MG cells were injected into the left and right flanks of athymic nude mice. D54MG tumor xenografts in both hind limbs were irradiated three times at $3 \mathrm{~Gy}$ over $24 \mathrm{~h}$ (right) or at 0 Gy (left). Optical images were acquired at different time points after injection into the tumor site with $1 \times 10^{10}$ vp of AdGRP78-BPeGFP. (b) To evaluate the levels of eGFP expression, D54MG tumors in the right hind limbs were irradiated three times at 3 Gy and the left hind limbs were untreated; the mice were then injected with $1 \times 10^{10} \mathrm{vp}$ per tumor of AdGRP78-BPeGFP vector. Optical images were acquired, and background-adjusted fluorescence was assessed for each irradiated (filled circle symbol) or untreated (open square symbol) tumor at different time points after Ad injection. (c) The irradiated-to-mock-irradiated (XRT/mock) ratios of fluorescence intensity were calculated for each individual animal. (d) To evaluate Luc expression $5 \times 10^{6}$ of D54MG cells were s.c. injected into both the left and the right flanks of athymic nude mice. Eleven days after cell injection, tumors in the left hind limbs were irradiated three times at $3 \mathrm{~Gy}$ and the right hind limbs were untreated. Mice were randomly divided into groups receiving $1 \times 10^{10} \mathrm{vp}$ per tumor of AdGRP78-BPLuc or Ad5Luc. Three days after Ad injection the animals were sacrificed, tumors were harvested and snap-frozen in ethanol/dry ice mix, and Luc reporter gene expression was assessed for each animal. Each point represents the RLU per mg total protein for each irradiated (filled circle symbol) or untreated (open square symbol) tumor tissue lysate. (e) The irradiated-to-mock-irradiated (XRT/mock) ratios were calculated for each individual animal with the RLU normalized by the protein concentration of the tumor tissue lysate. The XRT/mock ratios were significantly increased in mice following i.t. injection with fiber-modified AdGRP78-BPLuc in comparison with Ad5Luc-expressing wild-type fiber. Ad, adenovirus; eGFP, enhanced green fluorescent protein; GFP, green fluorescent protein; GRP78, glucose-regulated protein 78; Luc, luciferase; RLU, relative light units; s.c., subcutaneously; VP, viral particles; XRT, radiotherapy.

represents a powerful means of achieving targeted anti-glioma therapy, which has been rapidly translated into human clinical trials. ${ }^{49}$ Of note, a range of virotherapy agents have been employed for anti-cancer treatment in combination with XRT. ${ }^{50}$ In this regard, the ability to engineer conditionally replicating Ad to infect and replicate preferentially in tumor cells overexpressing XRT-induced neoantigens constitutes the key facet of their design allowing targeted action. It is hypothesized that the combination of transcriptional and transductional targeting strategies will operate in functional synergy to provide higher levels of tumor selectivity of oncolytic virotherapy agents.

In conclusion, we have developed a panel of fiber-modified Ads containing a gene encoding the GRP78-binding peptide inserted into the C-terminus of the fiber-fibritin knobless fusion protein. We have explored the utility of employing a transductional targeting approach for radiation-guided Ad gene transfer. We 
have evaluated reporter gene expression of fiber-modified Ad vectors in vitro and the use of a s.c. human glioma xenograft tumor model. Our results demonstrate that infection with fibermodified Ads resulted in increased gene transfer following XRT in comparison with mock-treated tumors. The results of preliminary studies using radiation-guided Ads in combination with XRT provide a novel strategy to link XRT and gene therapy for glioma.

\section{CONFLICT OF INTEREST}

The authors declare no conflict of interest.

\section{ACKNOWLEDGEMENTS}

This work was supported in part by 5P50CA101955 and 5R01CA154697 (SAK) and P30CA91842 Siteman Cancer Center, Alvin Siteman Cancer Research award, R21CA170169, R41CA196002, R01CA174966, R01CA125757 and Elizabeth and James McDonnell III Endowment (DEH). The authors would like to acknowledge Steve Mnich for help with eGFP imaging. The authors thank Dr Dinesh Thotala and Dr Andrei Laszlo for reviewing this manuscript.

\section{REFERENCES}

1 Talibi SS, Aweid B, Aweid O. Prospective therapies for high-grade glial tumours: a literature review. Ann Med Surg (Lond) 2014; 3: 55-59.

2 Cancer Genome Atlas Research Network. Comprehensive genomic characterization defines human glioblastoma genes and core pathways. Nature 2008; 455: 1061-1068.

3 Patel AP, Tirosh I, Trombetta JJ, Shalek AK, Gillespie SM, Wakimoto H et al. Singlecell RNA-seq highlights intratumoral heterogeneity in primary glioblastoma. Science 2014; 344: 1396-1401.

4 Kaliberov SA, Buchsbaum DJ. Chapter seven--cancer treatment with gene therapy and radiation therapy. Adv Cancer Res 2012; 115: 221-263.

5 Zhang WW. Development and application of adenoviral vectors for gene therapy of cancer. Cancer Gene Ther 1999; 6: 113-138.

6 Akli S, Caillaud C, Vigne E, Stratford-Perricaudet LD, Poenaru L, Perricaudet M et al. Transfer of a foreign gene into the brain using adenovirus vectors. Nat Genet 1993; 3: 224-228.

7 Bajocchi G, Feldman SH, Crystal RG, Mastrangeli A. Direct in vivo gene transfer to ependymal cells in the central nervous system using recombinant adenovirus vectors. Nat Genet 1993; 3: 229-234.

8 Davidson BL, Allen ED, Kozarsky KF, Wilson JM, Roessler BJ. A model system for in vivo gene transfer into the central nervous system using an adenoviral vector. Nat Genet 1993; 3: 219-223.

9 Ichikawa T, Tamiya T, Adachi Y, Ono Y, Matsumoto K, Furuta T et al. In vivo efficacy and toxicity of 5-fluorocytosine/cytosine deaminase gene therapy for malignant gliomas mediated by adenovirus. Cancer Gene Ther 2000; 7: 74-82.

10 Li H, Alonso-Vanegas M, Colicos MA, Jung SS, Lochmuller H, Sadikot AF et al. Intracerebral adenovirus-mediated p53 tumor suppressor gene therapy for experimental human glioma. Clin Cancer Res 1999; 5: 637-642.

11 Passarella RJ, Spratt DE, van der Ende AE, Phillips JG, Wu H, Sathiyakumar V et al. Targeted nanoparticles that deliver a sustained, specific release of Paclitaxel to irradiated tumors. Cancer Res 2010; 70: 4550-4559.

12 Gonzalez-Gronow M, Selim MA, Papalas J, Pizzo SV. GRP78: a multifunctional receptor on the cell surface. Antioxid Redox Signal 2009; 11: 2299-2306.

13 Tsai YL, Zhang Y, Tseng CC, Stanciauskas R, Pinaud F, Lee AS. Characterization and mechanism of stress-induced translocation of 78-kilodalton glucose-regulated protein (GRP78) to the cell surface. J Biol Chem 2015; 290: 8049-8064.

14 Belousova N, Korokhov N, Krendelshchikova V, Simonenko V, Mikheeva G, Triozzi PL et al. Genetically targeted adenovirus vector directed to CD40expressing cells. J Virol 2003; 77: 11367-11377.

15 Noureddini SC, Krendelshchikov A, Simonenko V, Hedley SJ, Douglas JT, Curiel DT et al. Generation and selection of targeted adenoviruses embodying optimized vector properties. Virus Res 2006; 116: 185-195.

16 He TC, Zhou S, da Costa LT, Yu J, Kinzler KW, Vogelstein B. A simplified system for generating recombinant adenoviruses. Proc Natl Acad Sci USA 1998; 95: 2509-2514.

17 Mittereder N, March KL, Trapnell BC. Evaluation of the concentration and bioactivity of adenovirus vectors for gene therapy. J Virol 1996; 70: 7498-7509.

18 Krasnykh VN, Mikheeva GV, Douglas JT, Curiel DT. Generation of recombinant adenovirus vectors with modified fibers for altering viral tropism. $J$ Virol 1996; 70: 6839-6846.
19 Reardon DA, Wen PY. Glioma in 2014: unravelling tumour heterogeneityimplications for therapy. Nat Rev Clin Oncol 2015; 12: 69-70.

20 Parisi S, Corsa P, Raguso A, Perrone A, Cossa S, Munafò T et al. Temozolomide and radiotherapy versus radiotherapy alone in high grade gliomas: a very long term comparative study and literature review. Biomed Res Int 2015; 2015: 620643.

21 Mittal S, Pradhan S, Srivastava T. Recent advances in targeted therapy for glioblastoma. Expert Rev Neurother 2015; 15: 935-946.

22 Stupp R, Hegi ME, Mason WP, van den Bent MJ, Taphoorn MJ, Janzer RC et al. Effects of radiotherapy with concomitant and adjuvant temozolomide versus radiotherapy alone on survival in glioblastoma in a randomised phase III study: 5year analysis of the EORTC-NCIC trial. Lancet Oncol 2009; 10: 459-466.

23 Eck SL, Alavi JB, Alavi A, Davis A, Hackney D, Judy K et al. Treatment of advanced CNS malignancies with the recombinant adenovirus H5.010RSVTK: a phase I trial. Hum Gene Ther 1996; 7: 1465-1482.

24 Ulasov IV, Borovjagin AV, Schroede BA, Baryshnikov AY. Oncolytic adenoviruses: a thorny path to glioma cure. Genes Dis 2014; 1: 214-226.

25 Stupp R, Mason WP, van den Bent MJ, Weller M, Fisher B, Taphoorn MJ et al. Radiotherapy plus concomitant and adjuvant temozolomide for glioblastoma. N Engl J Med 2005; 352: 987-996.

26 Dadey DY, Kapoor V, Khudanyan A, Urano F, Kim AH, Thotala D et al. The ATF6 pathway of the ER stress response contributes to enhanced viability in glioblastoma. Oncotarget 2016; 7: 2080-2092.

27 Tameire F, Verginadis II, Koumenis C. Cell intrinsic and extrinsic activators of the unfolded protein response in cancer: mechanisms and targets for therapy. Semin Cancer Biol 2015, 33: 3-15.

28 Hendershot LM. The ER function BiP is a master regulator of ER function. Mt Sinai $\lrcorner$ Med 2004; 71: 289-297

29 Xing X, Li Y, Liu H, Wang L, Sun L. Glucose regulated protein 78 (GRP78) is overexpressed in colorectal carcinoma and regulates colorectal carcinoma cell growth and apoptosis. Acta Histochem 2011; 113: 777-782.

30 Gray MJ, Mhawech-Fauceglia P, Yoo E, Yang W, Wu E, Lee AS et al. AKT inhibition mitigates GRP78 (glucose-regulated protein) expression and contribution to chemoresistance in endometrial cancers. Int J Cancer 2013; 133: 21-30.

31 Roller C, Maddalo D. The molecular chaperone GRP78/BiP in the development of chemoresistance: mechanism and possible treatment. Front Pharmacol 2013, 4: 10.

32 Arap MA, Lahdenranta J, Mintz PJ, Hajitou A, Sarkis AS, Arap W et al. Cell surface expression of the stress response chaperone GRP78 enables tumor targeting by circulating ligands. Cancer Cell 2004; 6: 275-284.

33 Zhang Y, Liu R, Ni M, Gill P, Lee AS. Cell surface relocalization of the endoplasmic reticulum chaperone and unfolded protein response regulator GRP78/BiP. J Biol Chem 2010; 285: 15065-15075.

34 Ajith TA. Strategies used in the clinical trials of gene therapy for cancer. J Exp Ther Oncol 2015; 11: 33-39.

35 Hallahan DE, Beckett MA, Kufe D, Weichselbaum RR. The interaction between recombinant human tumor necrosis factor and radiation in 13 human tumor cell lines. Int J Radiat Oncol Biol Phys 1990; 19: 69-74.

36 Weichselbaum RR, Hallahan DE, Beckett MA, Mauceri HJ, Lee H, Sukhatme V et al. Gene therapy targeted by radiation preferentially radiosensitizes tumor cells. Cancer Res 1994; 54: 4266-4269.

37 Hamdi M, Kool J, Cornelissen-Steijger P, Carlotti F, Popeijus HE, van der Burgt C et al. DNA damage in transcribed genes induces apoptosis via the JNK pathway and the JNK-phosphatase MKP-1. Oncogene 2005; 24: 7135-7144.

38 Martin M, Vozenin MC, Gault N, Crechet F, Pfarr CM, Lefaix JL. Coactivation of AP-1 activity and TGF-beta1 gene expression in the stress response of normal skin cells to ionizing radiation. Oncogene 1997; 15: 981-989.

39 Blalock WL, Weinstein-Oppenheimer C, Chang F, Hoyle PE, Wang XY, Algate PA et al. Signal transduction, cell cycle regulatory, and anti-apoptotic pathways regulated by IL-3 in hematopoietic cells: possible sites for intervention with antineoplastic drugs. Leukemia 1999; 13: 1109-1166.

40 Beetz A, Peter RU, Oppel T, Kaffenberger W, Rupec RA, Meyer M et al. NF-kappaB and AP- 1 are responsible for inducibility of the IL- 6 promoter by ionizing radiation in HeLa cells. Int J Radiat Biol 2000; 76: 1443-1453.

41 Datta R, Rubin E, Sukhatme V, Qureshi S, Hallahan D, Weichselbaum RR et al. lonizing radiation activates transcription of the EGR1 gene via CArG elements. Proc Natl Acad Sci USA 1992; 89: 10149-10153.

42 Hsu H, Rainov NG, Quinones A, Eling DJ, Sakamoto KM, Spear MA. Combined radiation and cytochrome CYP4B1/4-ipomeanol gene therapy using the EGR1 promoter. Anticancer Res 2003; 23: 2723-2728.

43 Mezhir JJ, Smith KD, Posner MC, Senzer N, Yamini B, Kufe DW et al. lonizing radiation: a genetic switch for cancer therapy. Cancer Gene Ther 2006; 13: 1-6.

44 Boothman DA, Lee IW, Sahijdak WM. Isolation of an X-ray-responsive element in the promoter region of tissue-type plasminogen activator: potential uses of X-ray-responsive elements for gene therapy. Radiat Res 1994; 138: S68-S71. 
45 McCarthy HO, Worthington J, Barrett E, Cosimo E, Boyd M, Mairs RJ et al. p21 ((WAF1))-mediated transcriptional targeting of inducible nitric oxide synthase gene therapy sensitizes tumours to fractionated radiotherapy. Gene Ther 2007; 14: 246-255.

46 Takahashi S, Saito S, Ohtani N, Sakai T. Involvement of the Oct-1 regulatory element of the gadd45 promoter in the p53-independent response to ultraviolet irradiation. Cancer Res 2001; 61: 1187-1195.

47 Daino K, Ichimura S, Nenoi M. Comprehensive search for X-ray-responsive elements and binding factors in the regulatory region of the GADD45a gene. J Radiat Res 2003; 44: 311-318.

48 Spencer DA, Young JS, Kanojia D, Kim JW, Polster SP, Murphy JP et al. Unlocking the promise of oncolytic virotherapy in glioma: combination with chemotherapy to enhance efficacy. Ther Deliv 2015; 6: 453-468.

49 Westphal M, Ylä-Herttuala S, Martin J, Warnke P, Menei P, Eckland D et al. Adenovirus-mediated gene therapy with sitimagene ceradenovec followed by intravenous ganciclovir for patients with operable high-grade glioma
(ASPECT): a randomised, open-label, phase 3 trial. Lancet Oncol 2013; 14: 823-833.

50 Touchefeu Y, Vassaux G, Harrington KJ. Oncolytic viruses in radiation oncology. Radiother Oncol 2011; 99: 262-270.

(c) (1) $\odot$ This work is licensed under a Creative Commons Attribution-

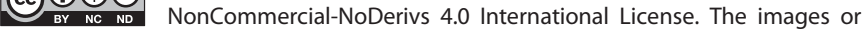
other third party material in this article are included in the article's Creative Commons license, unless indicated otherwise in the credit line; if the material is not included under the Creative Commons license, users will need to obtain permission from the license holder to reproduce the material. To view a copy of this license, visit http:// creativecommons.org/licenses/by-nc-nd/4.0/

(c) The Author(s) 2016 